National Marine

Fisheries Service

NOAA
Fishery Bulletin

as established in 1881 ๙
Spencer F. Baird

First U.S. Commissioner of Fisheries and founder of Fishery Bulletin

\begin{abstract}
When the blood of American horseshoe crabs (Limulus polyphemus) is extracted to create Limulus amebocyte lysate, the crabs are often subjected to warm temperatures and time out of water, in addition to blood loss. The goal of this study was to determine the effects of these 3 stressors on the locomotor activity and hemocyanin (HCY) levels of American horseshoe crabs. We found that a full bleeding treatment involving all 3 stressors had the biggest impact on mortality and HCY levels, followed by bleeding along with at least 1 other stressor. All of the treatments resulted in similar small changes in their overall activity and in the types of biological rhythms expressed. There was greater overall activity in animals that had higher HCY levels $(P<0.0001)$. We also found that HCY levels were lowest in the spring and early summer and highest in the late summer and fall. In each month, males had higher HCY levels than females. These results indicate that low HCY concentrations can negatively affect the health of horseshoe crabs. If biomedical facilities take sex differences and seasonal fluctuations in HCY levels into account, they might be able to reduce some of the deleterious effects of the bleeding process.
\end{abstract}

Manuscript submitted 23 January 2020. Manuscript accepted 20 July 2020. Fish. Bull. 118:225-239 (2020).

Online publication date: 13 August 2020 doi: 10.7755/FB.118.3.2

The views and opinions expressed or implied in this article are those of the author (or authors) and do not necessarily reflect the position of the National Marine Fisheries Service, NOAA.

\title{
Effects of the biomedical bleeding process on the behavior and hemocyanin levels of the American horseshoe crab (Limulus polyphemus)
}

\author{
Meghan Owings (contact author) ${ }^{1}$ \\ Christopher Chabot ${ }^{2}$ \\ Winsor Watson III \\ Email address for contact author: mwowings1@gmail.com \\ ${ }^{1}$ Department of Biological Sciences \\ School of Marine Sciences and Ocean Engineering \\ University of New Hampshire \\ 46 College Road \\ Durham, New Hampshire 03824 \\ ${ }^{2}$ Department of Biological Sciences \\ Plymouth State University \\ 17 High Street \\ Plymouth, New Hampshire 03264
}

Limulus amebocyte lysate, a substance that can be extracted from the blood of the American horseshoe crab (Limulus polyphemus), is widely used to test the sterility of pharmaceuticals and medical implants. In order to provide sufficient Limulus amebocyte lysate, approximately 600,000 American horseshoe crabs are bled each year (ASMFC, 2019). It is not clear if this level of harvest can be sustained because of the lethal and sublethal effects of the bleeding procedure. Findings from several studies indicate that blood extraction results in varying levels of mortality (reviewed in Krisfalusi-Gannon et al., 2018). Although the entire biomedical bleeding process involves several stressors, the blood removal itself results in increased rates of mortality compared with those of control animals (Rudloe, 1983; Kurz and James-Pirri, 2002), and the amount of blood removed has an impact on how many die from the procedure. When animals had $10-30 \%$ of their blood volume removed, only $8 \%$ of the animals died, but when $40 \%$ of their volume was removed, the mortality rate was 29\% (Hurton and Berkson, 2006).
Mortality rates associated with the full bleeding treatment, which includes some additional stressors described later, have ranged from $5 \%$ to $30 \%$ (Thompson, 1998; Walls and Berkson, 2000, 2003; Hurton and Berkson, 2006; Leschen and Correia, 2010; Anderson et al., 2013), with differential mortality rates between the sexes ( $15 \%$ for males and up to $29 \%$ for females; Leschen and Correia, 2010; James-Pirri et al., 2012).

When American horseshoe crabs are harvested and transported back and forth to the bleeding facilities, they are subjected to a variety of stressors, including exposure to air and warm temperatures. For example, they spend a significant amount of time out of water when they are left on the decks of boats, and on docks, or are in the trucks that transport them to and from bleeding facilities $\left(\mathrm{ASMFC}^{1}\right)$. In addition,

\footnotetext{
${ }^{1}$ ASMFC (Atlantic States Marine Fisheries Commission). 2012. 2012 review of the fishery management plan in 2011 for horseshoe crab (Limulus polyphemus), 15 p. Prepared by the ASMFC Horseshoe Crab Plan Review Team. ASMFC, Arlington, VA. [Available from website.]
} 
because they are often in direct sunlight on vessels and docks or are transported in trucks with poor temperature control $\left(\mathrm{ASMFC}^{1}\right)$, they are exposed to temperatures that are much warmer than the water from which they are captured. Finally, because up to $30 \%$ of their blood is removed, many of the important functions of hemolymph will be compromised (Novitsky, 1984; James-Pirri et al., 2012). The 6 major biomedical companies in the United States have slightly different collection, handling, and bleeding procedures; nonetheless, American horseshoe crabs must endure varying amounts of 3 stressors: air exposure, elevated temperatures, and blood loss.

Although mortality often occurs as a result of the biomedical bleeding process, it is not clear what parts of the process have the greatest impacts on the probability that animals will die during, or after, the procedure. Hurton and Berkson (2006) found that mortalities of American horseshoe crabs significantly increased when they exposed them to a combination of stressors, and studies of techniques in the capture of other marine species also have revealed that mortality is affected by the synergistic combination of multiple stressors (Schisler et al., 2000; Schulz and Dabrowski, 2001; Hatch and Blaustein, 2003). Therefore, Hurton and Berkson (2006) highlighted the need for studying the cumulative effect of the multiple stressors that American horseshoe crabs experience during the bleeding process. One of the major goals of this study was to identify which of these stressors contributes to the behavioral and physiological deficits (described later) that have been observed in some American horseshoe crabs subjected to the entire process.

American horseshoe crabs that survive the biomedical bleeding process may take some time to fully recover. For example, Novitsky (1984) found that it takes 3-7 d for a bled American horseshoe crab to regain its total blood volume and up to 4 months for amebocytes to return to baseline levels. James-Pirri et al. (2012) reported that bled American horseshoe crabs released back into their natural environment had a random direction of movement compared with the movement patterns of control animals, and Anderson et al. (2013) found that the bleeding process led to decreases in activity levels, expression of circatidal rhythms, linear and angular movement velocities, and hemocyanin (HCY) levels. Finally, we recently found that, although bled animals released back into their natural habitat had seasonal movement patterns and overall activity levels that were similar to control animals, bled females spawned less during the 2 -week period after they were released (Owings et al., 2019). This result motivated us to examine the effect of bleeding in a more controlled environment, one in which we could more continuously monitor behavior and HCY levels of animals.

Because of the variety of important functions of $\mathrm{HCY}$, reductions in HCY levels due to bleeding could lead to decreases in fitness of the American horseshoe crab. Hemocyanin is important for transporting oxygen (Redmond, 1955; Mangum, 1980), eliciting the primary immune response (Coates et al., 2011), contributing to wound repair and cuticle hardening (Adachi et al., 2005a), molting (Adachi et al., 2005a, 2005b; Kuballa and Elizur, 2008; Kuballa et al., 2011; Glazer et al., 2013), and osmoregulation (Paul and Pirow, 1998). Furthermore, environmental conditions, such as increased temperatures and air exposure, can affect HCY concentrations (Mangum, 1980; Burnett, 1988; Coates et al., 2012). In fact, the combination of warm temperatures, which elevate the metabolic rate of animals and reduce the amount of oxygen in the water, air exposure, which makes it harder for gills to obtain oxygen, and blood loss, which makes oxygen transportation more difficult, can compromise the ability of the American horseshoe crab to provide sufficient oxygen to cells in need. Therefore, the combination of stressors associated with the bleeding process could have much more severe consequences than blood loss alone.

In this study, our main objective was to determine which of the 3 stressors or combination of these stressors (Table 1) had the largest impact on the behavior and physiology of the American horseshoe crab. Animals were collected from the Great Bay Estuary in Durham, New Hampshire, baseline levels of HCY and locomotor activity were obtained, and subsets of the animals were exposed to each stressor combination (e.g., bled and exposed to air, unbled and exposed to air, and bled and elevated temperatures). Then we monitored their behavior and HCY levels for 2 weeks posttreatment in the laboratory.

\section{Materials and methods}

\section{Animal collection and experimental setup}

In 2016, 48 male American horseshoe crabs were collected by scuba divers at Fox Point in the Great Bay Estuary during June-October. In 2017, 63 female American horseshoe crabs were collected by scuba divers at Fox Point in June and July. All captured crabs were brought back to the University of New Hampshire Jackson Estuarine Laboratory (JEL), where an initial blood sample was collected and animals were fitted with $\mathrm{HOBO}^{2}$ accelerometers (HOBO Pendant G Data Loggers, Onset Computer Corp., Bourne, MA). The HOBO accelerometers were used to record triaxial orthogonal measurements of the acceleration (in meters per second) of individual American horseshoe crabs, and they were programmed to record a reading every minute. The accelerometers were attached to the dorsal carapace of each individual by first creating a harness, with 2 cable ties attached to the center of the prosoma with duct tape and cyanoacrylate, and then placing the accelerometer faceup in the harness and fastening cable ties over it. This arrangement made it relatively easy to weekly remove the accelerometers, download the data, and then replace them again with minimal disturbance of the animals.

\footnotetext{
${ }^{2}$ Mention of trade names or commercial companies is for identification purposes only and does not imply endorsement by the National Marine Fisheries Service, NOAA.
} 


\begin{tabular}{|c|c|c|c|c|c|}
\hline \multicolumn{6}{|c|}{ Table 1} \\
\hline \multicolumn{6}{|c|}{$\begin{array}{l}\text { The combinations of stressors and the time periods for treatments to which groups } \\
\text { of American horseshoe crabs (Limulus polyphemus), collected in the Great Bay } \\
\text { Estuary in New Hampshire, were exposed during laboratory experiments in } 2016 \\
\text { and } 2017 \text {. Treatments included } 1 \text { or more of the following } 3 \text { stressors: exposure to } \\
\text { air, exposure to heat, or bleeding. These } 3 \text { stressors were chosen to simulate what } \\
\text { American horseshoe crabs experience during the biomedical bleeding process, as } \\
\text { well as during capture and transport. Several of the treatments were repeated in } \\
2016 \text { and } 2017 \text {. In } 2017 \text {, for some of the groups exposed to air, animals were covered } \\
\text { with moist burlap. The average water temperature for each month is also provided. }\end{array}$} \\
\hline \multirow[b]{3}{*}{ Treatment group } & \multicolumn{5}{|c|}{ Time period } \\
\hline & \multicolumn{3}{|c|}{2016} & \multicolumn{2}{|c|}{2017} \\
\hline & June & August & October & June & July \\
\hline Temperature & $18.4^{\circ} \mathrm{C}$ & $22.3^{\circ} \mathrm{C}$ & $14.0^{\circ} \mathrm{C}$ & $17.7^{\circ} \mathrm{C}$ & $20.7^{\circ} \mathrm{C}$ \\
\hline Control & $x$ & & & $x$ & $x$ \\
\hline Bled & $x$ & & & $x$ & $x$ \\
\hline Air & & $x$ & & & \\
\hline Air (burlap) & & & & $x$ & $x$ \\
\hline Air and bled & & $x$ & & & \\
\hline Air and bled (burlap) & & & & $x$ & $x$ \\
\hline Air and heat & & & $x$ & & \\
\hline Air and heat (burlap) & & & & $x$ & $x$ \\
\hline Air, heat, and bled & & & $x$ & $x$ & $x$ \\
\hline Air, heat, and bled (burlap) & & & & $x$ & $x$ \\
\hline
\end{tabular}

Animals were then placed into individual circular mesh enclosures (1-m diameter) within larger flow-through 850 -L tanks $(183 \times 92 \times 50 \mathrm{~cm})$ filled with estuarine water and located outside of JEL. There were 2 enclosures per tank, and they were exposed to natural light and a dark cycle (enclosures were not covered). HOBO temperature data loggers (Onset Computer Corp.) were placed in the tanks to monitor the water temperature for the duration of each of the experiments. Behavioral data were collected for 1 week prior to exposure of animals to a given treatment, and then blood samples were taken and data were downloaded from the accelerometers.

Once the accelerometers were reattached, individuals underwent their designated treatment (described later) and then were returned to their tanks. Animals were kept in these tanks for 2 weeks after undergoing treatment, and their activity was monitored continuously, as described previously. Additional hemolymph samples were taken from each animal 7 and $14 \mathrm{~d}$ after their treatments.

\section{Treatment groups}

Animals were assigned to different treatment groups on the basis of which of the following 3 stressors, or combination of these stressors, to which they were exposed: bleeding, air exposure, and heat (Table 1). All experiments were carried out during June-October of 2016 and June-July of 2017. In 2016, 3 trials were completed, with 2 treatment groups of 8 animals each, per trial. In 2017, 2 trials were carried out, 1 trial in June and 1 trial in July, and each trial involved all of the treatment groups. There were 5 animals per treatment group in June and 4 animals per group in July.

\section{Biomedical bleeding procedure}

After all animals were monitored for baseline activity for 1 week, another 1-mL hemolymph sample was taken, and they were exposed to their randomly designated stressors (Table 2). The full bleeding treatment took $52 \mathrm{~h}$, a time that was chosen to mimic the procedure used in several previously published studies (Hurton and Berkson, 2006; Leschen and Correia, 2010; Anderson et al., 2013; Owings et al., 2019) and to be similar to what animals may experience when bled by companies in the biomedical industry. First, American horseshoe crabs were placed in 189-L plastic barrels, and HOBO temperature data loggers were placed in each of the barrels. Then, the barrels were placed outside of JEL for $4 \mathrm{~h}$, or next to a space heater in the JEL greenhouse, depending upon the temperature and ambient sunlight during the selected day; mean temperature during this time, for all trials, was $31.5^{\circ} \mathrm{C}$ (standard deviation [SD] 1.9). This step was designed to replicate the duration of time spent on the deck of a boat or on a dock in the summer prior to transport to a biomedical bleeding facility.

After the first $4 \mathrm{~h}$, the barrels were placed in the back of a car and driven around for an additional $4 \mathrm{~h}$ to simulate time spent in a truck traveling to a bleeding facility 


\section{Table 2}

Summary of the schedule of treatment activities for each experiment conducted in 2016 and 2017 on American horseshoe crabs (Limulus polyphemus) collected in the Great Bay Estuary in New Hampshire. Animals were assigned to different treatment groups and exposed to stressors to determine their effects on locomotor activity and hemocyanin levels.

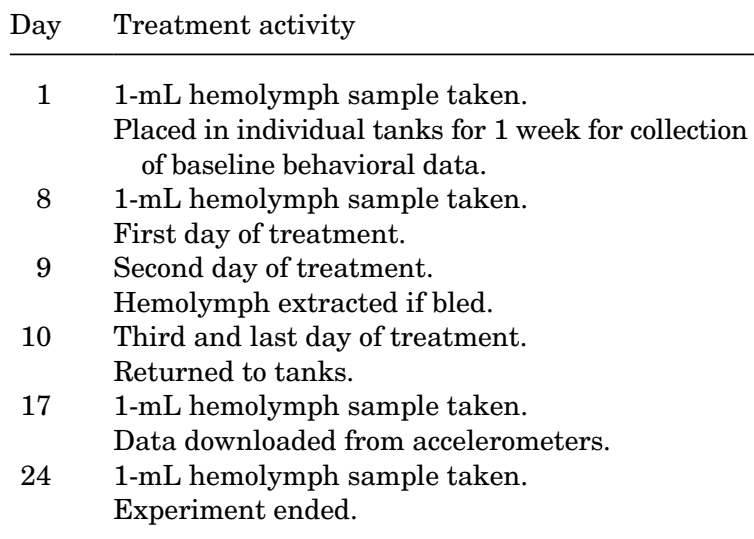

$\left(23.3^{\circ} \mathrm{C}\right.$ [SD 2.4]). Then, the barrels were placed indoors for $16 \mathrm{~h}$ at JEL to simulate time spent overnight at a bleeding facility $\left(20.0^{\circ} \mathrm{C}\right.$ [SD 2.1]). Finally, 30\% of their hemolymph was extracted (Hurton et al., 2005), and they were returned to their barrels where they remained for another $24 \mathrm{~h}$ to replicate a second night at a bleeding facility $\left(19.4^{\circ} \mathrm{C}\right.$ [SD 1.9]). The barrels were then placed back into a car for $4 \mathrm{~h}\left(22.3^{\circ} \mathrm{C}\right.$ [SD 2.2]) to simulate transportation back to the dock, where they would be loaded on vessels and returned to their capture location. Lastly, all animals were returned to their respective flow-through estuarine-water tanks, and their activity and HCY levels were monitored for another 2 weeks.

Control animals remained in their tanks throughout the duration of the experiment, except when blood samples were collected or data were downloaded from accelerometers. Animals that were in the control group also remained in the outdoor tanks, except for when $30 \%$ of their hemolymph was extracted on day 10 and for the brief periods of time when blood samples were collected approximately every 7-10 d. The animals that were exposed to one or more of the stressors were treated as outlined as follows, and each stressor was provided in the same manner as described previously for the full treatment:

- Bled: animals were subjected to hemolymph extraction on the second day of treatment.

- Air: on the first day of treatment, animals were placed inside the barrels inside JEL for the first $4 \mathrm{~h}$. They were not left outside in direct sunlight or next to a space heater.

- Heat: animals were exposed to direct sunlight or next to a space heater for the first $4 \mathrm{~h}$.
- Burlap: animals were treated like those in the group exposed to air but were covered with moist burlap when they were in the barrels.

- Two stressors: animals were treated just like those exposed to the full treatment, except at least one of the stressors was omitted. For example, animals exposed to air and bled were treated the same as those subjected to the full treatment, but they were not exposed to heat while they were in the barrels.

- All 3 stressors (full treatment): described previously.

\section{Hemolymph extraction}

Hemolymph was extracted following the procedures of Armstrong and Conrad (2008) and Anderson et al. (2013). First, the membrane between the prosoma and opisthosoma was exposed and cleaned with $70 \%$ ethanol. Then an 18-gauge needle was inserted through the membrane and into the underlying heart, and hemolymph was withdrawn and placed in pre-chilled $50-\mathrm{mL}$ conical tubes. An estimated $30 \%$ of the total hemolymph volume was extracted, if possible. The tubes containing the extracted blood were then placed on ice until further examination. Total hemolymph volume for each individual was calculated by using the following equation from Hurton et al. (2005):

$$
H=25.7 \mathrm{e}^{0.1928(\mathrm{IO})} \text {; }
$$

where $H=$ hemolymph volume (in milliliters); and

$I O=$ interocular width (in centimeters).

Concentrations of HCY (in milligrams per milliliters) were measured by using a modified procedure from Coates et al. (2012) and Anderson et al. (2013). Briefly, hemolymph samples were centrifuged for $10 \mathrm{~min}$ at $3000 \mathrm{~g}$ and $4^{\circ} \mathrm{C}$. Then, an aliquot of hemolymph was diluted (1:100) in 0.1 M Tris-HCl buffer ( $\mathrm{pH}$ 7.5) in a quartz cuvette with a path length of $1 \mathrm{~cm}$. The absorbance was measured at $280 \mathrm{~nm}$ on an Ultrospec 3100 pro UV/Visible spectrophotometer (Biochrom Ltd., Cambridge, UK). Values were standardized by using a predetermined absorption coefficient of $1.39 \mathrm{mg} / \mathrm{mL} \mathrm{HCY}$ solution (Coates et al., 2012). This value was verified by using a Pierce Modified Lowry Protein Assay Kit (ThermoFisher Scientific Inc., Waltham, MA).

\section{Data analyses}

Because of variations in the baseline data for all the animals exposed to treatments, data were converted and are shown as percentages of baseline for HCY levels and overall activity. This conversion or normalization approach also allowed us to pool treatment groups together (Table 3), except for the air, heat, and bled groups between 2016 and 2017 because there were significant differences in baseline $\mathrm{HCY}$ and activity levels between these groups in the these years as well as a large difference in water temperatures (2016: $14.0^{\circ} \mathrm{C}$ [SD 1.9]; 2017: $19.2^{\circ} \mathrm{C}$ [SD 1.7]).

Multivariate analyses of variance (MANOVA) were used to test for effects of time and treatment groups on HCY 


\section{Table 3}

Treatment groups for which data were pooled in analyses of the effects of stressors on American horseshoe crabs (Limulus polyphemus) in laboratory experiments conducted in 2016 and 2017. Treatments included 1 or more of the following 3 stressors: exposure to air, exposure to heat, or bleeding. For every treatment that was repeated more than one time, data for baseline levels of hemocyanin and activity, and for water temperatures, were pooled, except for data from applications of the full bleeding treatment (all 3 stressors) in 2016, because of differences in baseline data and water temperatures between 2016 and 2017. Data from the only 2 experiments involving the full treatment in 2017 were grouped because of similarities in baseline hemocyanin and activity levels, as well as in water temperatures. In 2017, for some of the groups exposed to air or heat, animals were covered with moist burlap. The time periods of treatments and the average water temperature for each month are also provided. Animals used in experiments were collected in the Great Bay Estuary in New Hampshire.

\begin{tabular}{|c|c|c|c|c|c|c|}
\hline \multirow[b]{3}{*}{ Treatment group } & \multicolumn{5}{|c|}{ Time period } & \multirow[b]{3}{*}{ Pooled } \\
\hline & \multicolumn{3}{|c|}{2016} & \multicolumn{2}{|c|}{2017} & \\
\hline & June & August & October & June & July & \\
\hline Temperature & $18.4^{\circ} \mathrm{C}$ & $22.3^{\circ} \mathrm{C}$ & $14.0^{\circ} \mathrm{C}$ & $17.7^{\circ} \mathrm{C}$ & $20.7^{\circ} \mathrm{C}$ & \\
\hline Control & $\times$ & & & $\times$ & $\times$ & Yes \\
\hline Bled & $x$ & & & $x$ & $x$ & Yes \\
\hline Air & & $x$ & & & & No \\
\hline Air (burlap) & & & & $x$ & $x$ & Yes \\
\hline Air and bled & & $x$ & & & & No \\
\hline Air and bled (burlap) & & & & $x$ & $x$ & Yes \\
\hline Air and heat & & & $x$ & & & No \\
\hline Heat (burlap) & & & & $x$ & $x$ & Yes \\
\hline Air, heat, and bled & & & $x$ & $x$ & $x$ & 2016: No; 2017: Yes \\
\hline Air, heat, and bled (burlap) & & & & $x$ & $x$ & Yes \\
\hline
\end{tabular}

levels and on overall activity. Two-way analyses of variance were also used to test for effects of different months and years, as well as of different months and sexes, on HCY levels. Tukey's honestly significant difference (HSD) post hoc test was used to examine significant differences between means of treatment groups for HCY and overall activity levels across different months, years, and sexes, with a threshold significance level $(\alpha)$ of 0.05 . Unpaired Student's $t$-tests were used to compare baseline HCY levels in animals that died with those in animals that survived. Correlation and linear regression analyses were used to determine relationships between HCY concentrations and overall activity levels.

An acceleration threshold of $0.1 \mathrm{~m} / \mathrm{s}^{2}$ (Watson et al., 2016) was used to classify an animal as being either active or inactive. Then these data were examined in 5-min bins, and if an animal exceeded the $0.1 \mathrm{~m} / \mathrm{s}^{2}$ threshold during any of the minutes in that 5-min bin, it was considered to have been active for that 5 -min period. These values were used to create actograms by using ActogramJ and were analyzed to determine the types of rhythms expressed by animals (Schmid et al., 2011). Specifically, the LombScargle method was used to determine when animals had significant circatidal $(\sim 12.4 \mathrm{~h})$ or daily $(\sim 24 \mathrm{~h})$ rhythms, with peaks exceeding an $\alpha$ of 0.001 (tidal range: $10-14 \mathrm{~h}$; daily range: $22-26 \mathrm{~h}$ ). Animals were considered arrhythmic if no significant peaks were observed in either range).

\section{Results}

\section{Mortality}

Combined mortality rates varied across the different experimental groups, and with the exception of the control group, there was at least one mortality resulting from each of the 3 different individual stressors (air exposure, heat, and bleeding) (Table 4). The overall mortality rate from all of the treatment groups, not including control animals, was $17 \%$. All mortalities (number of samples $[n]=15$ ) occurred $1-2 \mathrm{~d}$ posttreatment, except for the death of one animal in the group exposed to all stressors that died $12 \mathrm{~d}$ posttreatment.

In 2016 , when we used all males, there were only 2 mortalities throughout all of the treatment groups (Table 4). One mortality was in the bled group $(n=7)$, and the second was in the group bled and exposed to air $(n=7)$. In 2017, we used all females, and there were 13 mortalities. In June 2017, there were 4 mortalities, all in American horseshoe crabs that received the full bleeding treatment. In July 2017, there were 9 mortalities, including 6 of the 8 animals in the full bleeding treatment groups (with and without burlap). It should be noted that the water temperatures were warmer in July than in June (average: $17.7^{\circ} \mathrm{C}$ [SD 2.1] in June and $20.7^{\circ} \mathrm{C}$ [SD 1.2] in July), and this difference in temperatures might have been one reason why there were more mortalities in July. 


\section{Table 4}

Number of mortalities and mortality rates of American horseshoe crabs (Limulus polyphemus) in each of the different treatment groups of experiments that exposed animals to air, heat, or bleeding. Several of the treatments were repeated in 2016 and 2017. In 2017, for some of the groups exposed to air, animals were covered with moist burlap. The time periods of treatments and the average water temperature are provided for each month. Mortalities are given as the number of animals that died per the number of animals in a treatment, and mortality rates are given as percentages. Animals used in experiments were collected in the Great Bay Estuary in New Hampshire.

\begin{tabular}{|c|c|c|c|c|c|c|}
\hline \multirow[b]{3}{*}{ Treatment group } & \multicolumn{5}{|c|}{ Time period } & \multirow{3}{*}{$\begin{array}{c}\text { Combined } \\
\text { mortality rate }\end{array}$} \\
\hline & \multicolumn{3}{|c|}{2016} & \multicolumn{2}{|c|}{2017} & \\
\hline & June & August & October & June & July & \\
\hline Temperature & $18.4^{\circ} \mathrm{C}$ & $22.3^{\circ} \mathrm{C}$ & $14.0^{\circ} \mathrm{C}$ & $17.7^{\circ} \mathrm{C}$ & $20.7^{\circ} \mathrm{C}$ & \\
\hline Control & $0 / 8$ & & & $0 / 4$ & $0 / 4$ & $0 \%$ \\
\hline Bled & $1 / 7 ; 14 \%$ & & & $0 / 5$ & $0 / 4$ & $6 \%$ \\
\hline Air & & $0 / 8$ & & & & $0 \%$ \\
\hline Air (burlap) & & & & $0 / 5$ & $2 / 4 ; 50 \%$ & $22 \%$ \\
\hline Air and bled & & $1 / 7 ; 14 \%$ & & & & $14 \%$ \\
\hline Air and bled (burlap) & & & & $0 / 4$ & $1 / 4 ; 25 \%$ & $13 \%$ \\
\hline Air and heat & & & $0 / 7$ & & & $0 \%$ \\
\hline Air and heat (burlap) & & & & $0 / 4$ & $0 / 4$ & $0 \%$ \\
\hline Air, heat, and bled & & & $0 / 8$ & $2 / 4 ; 50 \%$ & $4 / 4 ; 100 \%$ & 2016: $0 \% ; 2017: 75 \%$ \\
\hline Air, heat, and bled (burlap) & & & & $2 / 5 ; 40 \%$ & $2 / 4 ; 50 \%$ & $44 \%$ \\
\hline
\end{tabular}

\section{Hemocyanin levels}

Effects of different treatments The average baseline HCY level for all animals was $40 \mathrm{mg} / \mathrm{mL}$ (SD 20), with a maximum value of $96 \mathrm{mg} / \mathrm{mL}$ and a minimum value of $2 \mathrm{mg} / \mathrm{mL}$. Because of this variability in the initial HCY levels, data are expressed as percent changes from the baseline levels. Every treatment group had a decrease over time in HCY levels from the baseline concentration, including the control group (MANOVA: $F_{(9,240)}=6.09, P<0.0001$ ) and all groups combined (MANOVA: $\left.F_{(2,240)}=44.5, \quad P<0.0001\right)$, but changes were more pronounced in certain groups (Fig. 1). There was a significant interaction between treatment and time on HCY levels (MANOVA: $F_{(18,240)}=2.112, P=0.006$ ). Post hoc analyses revealed that the HCY concentrations in the control group and the groups exposed to air (with burlap), and heat (with burlap) treatments (data not shown) were significantly higher than those of the group that received the full bleeding treatment (air, heat, and bled) over time (Tukey's HSD test: $P<0.05$ ).

Seasonal differences Male American horseshoe crabs were collected from

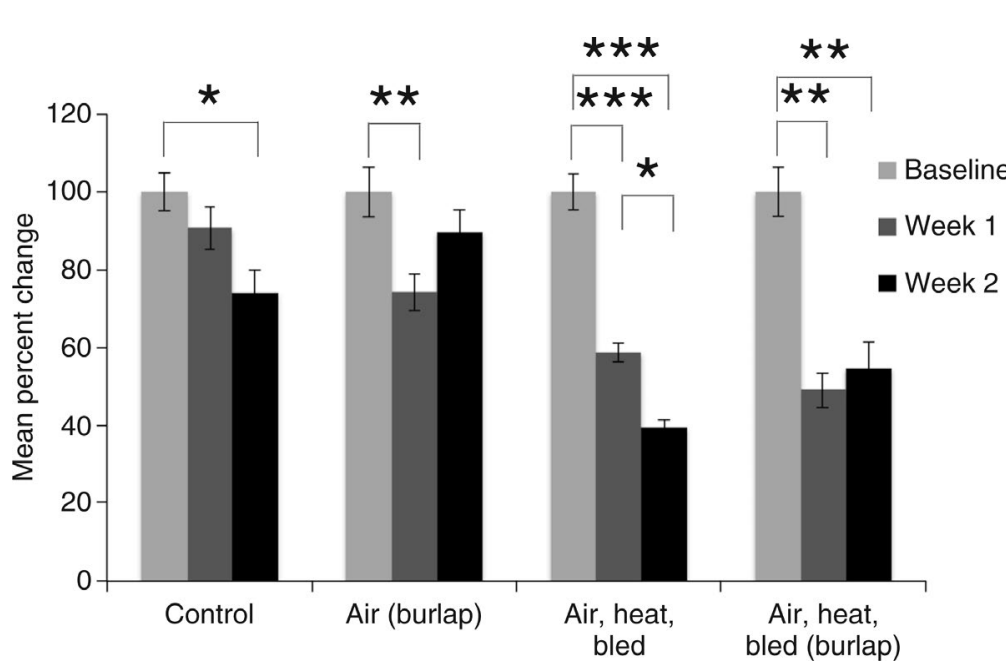

Figure 1

Mean percent change in hemocyanin concentrations of American horseshoe crabs (Limulus polyphemus) from baseline levels before treatments to levels 1 and 2 weeks after exposure to stressors in laboratory experiments conducted in 2016 and 2017. The treatment groups included a control group (number of animals $[n]=16$ ), a group of animals exposed to air only and covered with moist burlap $(n=7)$, and groups of animals exposed to air, heat, and bleeding without $(n=8)$ and with $(n=5)$ a burlap cover. Significant differences between baseline levels and levels 1 and 2 weeks after treatment are denoted with asterisks: $P<0.05(*), P<0.01(* *)$, and $P<0.001(* * *)$. Error bars indicate standard errors of the mean. Animals used in experiments were collected in the Great Bay Estuary in New Hampshire. 


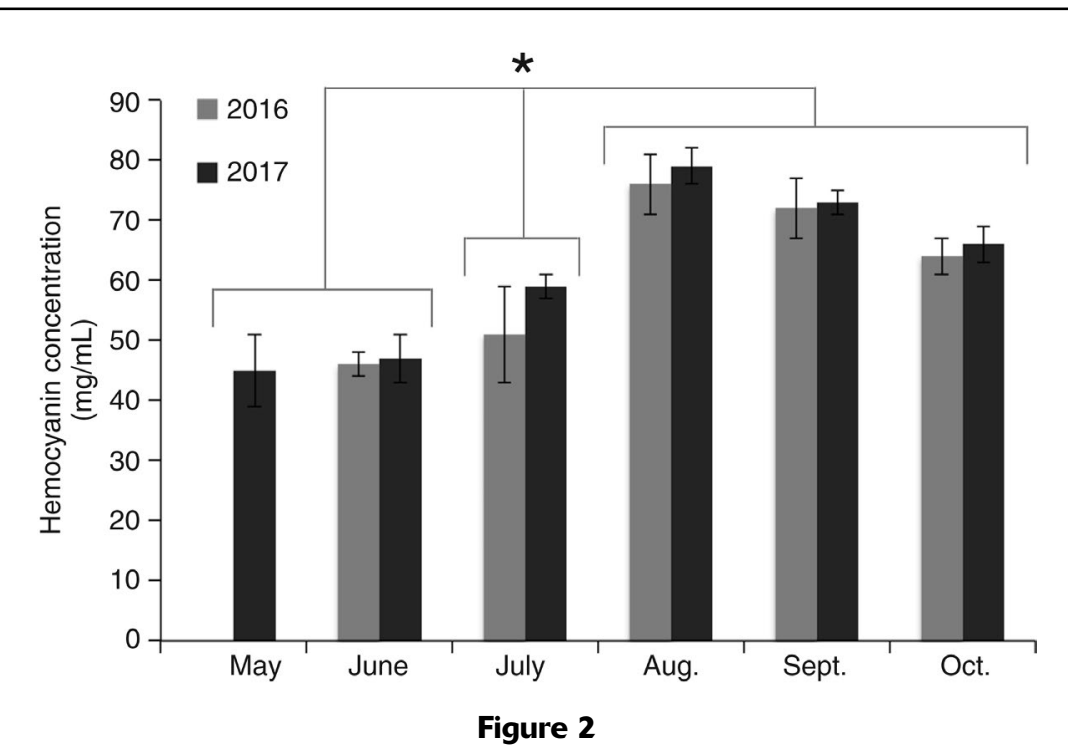

Monthly mean hemocyanin concentrations of male American horseshoe crabs ary in New Hampshire. The numbers of animals for which hemocyanin concentrations were measured in 2016 and 2017 are respectively 0 and 12 in May, 16 and 10 in June, 3 and 31 in July, 16 and 38 in August, 16 and 15 in September, and 16 and 8 in October. Significant differences between months $(P<0.001)$ are denoted with an asterisk (*). Error bars indicate the standard errors of the mean. (Limulus polyphemus) collected during 2016 and 2017 in the Great Bay Estu-

$F_{(1,222)}=23.27, P<0.0001$ ) (Fig. 3), with males having significantly higher HCY levels in all months than females, except in July and October.

Relationship between hemocyanin levels and mortality Because of the higher number of mortalities in 2017 (13) than in 2016 (2), only data from 2017 were used for this analysis. The average HCY concentration for the animals in the groups that did not have mortalities was $23 \mathrm{mg} / \mathrm{mL}$ (SD 14). In contrast, the baseline HCY level in animals that died $(n=14)$ was $13 \mathrm{mg} / \mathrm{mL}$ (SD 9), which is significantly lower than that in animals that survived ( $n=21 ; 30 \mathrm{mg} / \mathrm{mL}$ [SD 14]; unpaired Student's $t$-test: $P=0.008)$. In general, animals that had low baseline levels at the start of treatment, which included a combination of stressors, were at a greater risk of dying from the procedure.

Combined effects of stressors and hemocyanin levels on mortality Using all of the data previously presented here, we were able to determine a HCY threshold of mortality risk for animals that are col-

June through October in both 2016 and 2017. Males obtained in the fall had significantly higher HCY levels than those collected in the spring in both years (MANOVA: $\left.F_{(5,240)}=30.31, P<0.0001\right)$, and overall HCY levels were significantly higher in 2017 than in 2016 (MANOVA: $\quad F_{(1,240)}=76.36, \quad P<0.0001$ ) (Fig. 2). Results of post hoc analyses indicate that animals collected in May and June had similar HCY levels, animals collected in July had HCY concentrations that were significantly higher than the levels of animals captured in May and June, and animals collected in August-October had similar HCY concentrations, the highest average HCY levels of around $70 \mathrm{mg} / \mathrm{mL}$ (Tukey's HSD test: $P<0.05)$. Animals collected in August had the highest peak in HCY levels among animals captured in any month, and animals collected in May had the lowest levels.

In 2017, hemolymph samples were collected from both males and females, and the HCY concentrations followed the same seasonal variations discussed previously, with both males and females having the lowest levels in the spring. In addition, we found some differences in monthly HCY levels (MANOVA: $F_{(5,222)}=26.63$, $P<0.0001)$ between the sexes (MANOVA: lected for the bleeding process (Fig. 4). For the animals that were collected between 2016 and 2017, the maximum baseline HCY level was $120 \mathrm{mg} / \mathrm{mL}$, and the average starting baseline level was $24 \mathrm{mg} / \mathrm{mL}$. Animals that died as a

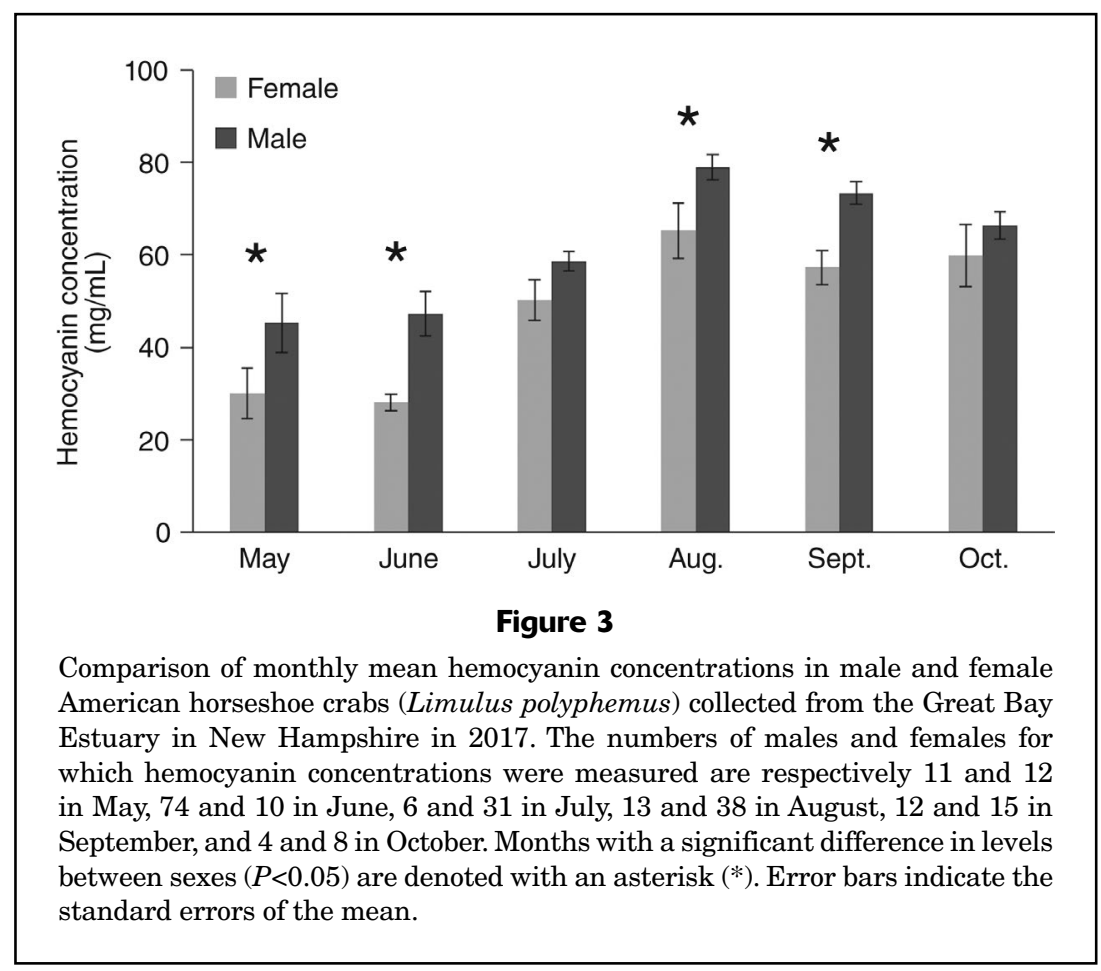




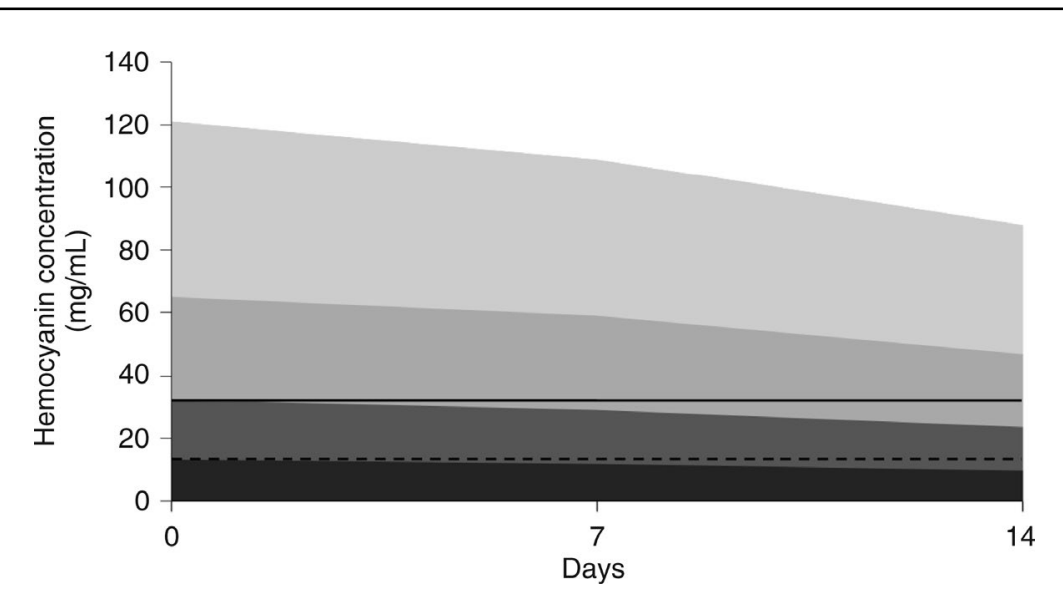

Figure 4

Hemocyanin (HCY) levels of American horseshoe crabs (Limulus polyphemus), collected from the Great Bay Estuary in New Hampshire, in relation to their mortality risk during the $14 \mathrm{~d}$ after exposure to stressors in laboratory experiments conducted in 2016 and 2017. The solid black line indicates the mortality risk threshold of $32 \mathrm{mg} / \mathrm{mL}$. Animals with initial HCY levels above this value rarely died during the bleeding process. The dashed black line represents the most critical threshold of $13 \mathrm{mg} / \mathrm{mL}$, a baseline concentration at which animals were most likely to die as a result of the bleeding process. Shades of gray indicate the health status of animals based on HCY levels before the bleeding process, with darker shades indicating low health: animals were not as affected by bleeding if they had HCY concentrations of $32-65 \mathrm{mg} / \mathrm{mL}$ and especially if their levels were $65-120 \mathrm{mg} / \mathrm{mL}$.

increased significantly in week 1 and then went back down in week 2 .

Biological rhythms Across treatment groups, and over time, American horseshoe crabs expressed a variety of daily and tidal rhythms, and some animals were arrhythmic. Initially, $37 \%$ of the animals exhibited tidal rhythms, $38 \%$ had daily rhythms, and $25 \%$ expressed no statistically significant rhythms. Although the majority of control animals (14 of 16 crabs) maintained their baseline rhythms throughout the duration of the study (Fig. 6), a number of the animals in the other treatment groups shifted from one type of rhythm to another at some point after the control week. It did not appear as if burlap made much difference; therefore, for this analysis, we grouped similar treatments that did or did not involve the use of burlap. We found that only 2-3 animals in each treatment group, including those that were exposed to the full treatment ( 2 of 12 crabs), switched their rhythms in the week following the treatment, except the air and heat treatment group. In this group, almost half (7 of 15) of the American horseshoe crabs switched rhythms

result of being exposed to one of the treatments tended to have lower levels (average: $13 \mathrm{mg} / \mathrm{mL}$; range: $2-32 \mathrm{mg} / \mathrm{mL}$ ) than those that survived (average: $46 \mathrm{mg} / \mathrm{mL}$ [SD 19]). Therefore, there appears to be a healthy threshold level of HCY (13 mg/mL), and if animals that have HCY levels below this threshold are bled, they have a much greater probability of not surviving the procedure (Fig. 4). In addition, HCY levels tend to decrease in American horseshoe crabs held in captivity; hence, they might fall below this healthy threshold value of HCY over time (Fig. 4). For example, in control animals, we saw an average $10 \%$ decrease in HCY levels over a 1-week period (7 d) and a $27 \%$ decrease over a 2 -week period ( $14 \mathrm{~d}$ ) from baseline levels (day 0) (Fig. 2). Therefore, animals that start with low levels of HCY, and that are held in captivity before they are bled, are least likely to survive.

\section{Effects of bleeding and associated stressors on crab behavior}

Overall activity levels Overall, there were no consistent changes in the overall activity levels of American horseshoe crabs exposed to any of the treatments (Fig. 5). In comparison with their activity during the 1-week control period, only the groups exposed to air, or air and heat, expressed a significant change in activity either 1 or 2 weeks after their respective treatments (Table 1). The activity levels of animals in the group exposed to air were significantly lower in week 2 than in the control week, and the activity of the group exposed to air and heat immediately after their treatments, and then they tended to continue expressing that pattern for the rest of the study.

Relationship between activity and hemocyanin levels Taken together, the data reported here indicate that a reduction in HCY levels reduces the overall activity of American horseshoe crabs and increases the likelihood that animals could die if exposed to other stressors, such as bleeding. Therefore, we examined the relationship between overall activity levels and HCY levels in 87 animals in both 2016 and 2017, and we found that animals that were the most active also tended to have higher HCY levels $\left(n=87 ; F_{(1,86)}=17.01, P<0.0001\right.$, coefficient of multiple determination $\left[R^{2}\right]=0.16$ ) (Fig. 7).

\section{Discussion}

The main objective of this study was to determine which of the stressors, or combination of stressors, associated with the biomedical bleeding process has the greatest impact on the physiology and behavior of the American horseshoe crab. Overall, we found that 1) the full bleeding treatment (exposed to air and heat and bled) had the largest effect on mortality and HCY concentrations, 2) animals with a baseline HCY level $<13 \mathrm{mg} / \mathrm{mL}$ were most likely to die or be impaired by the bleeding process, and 3) lower HCY levels were correlated with lower activity levels. In 


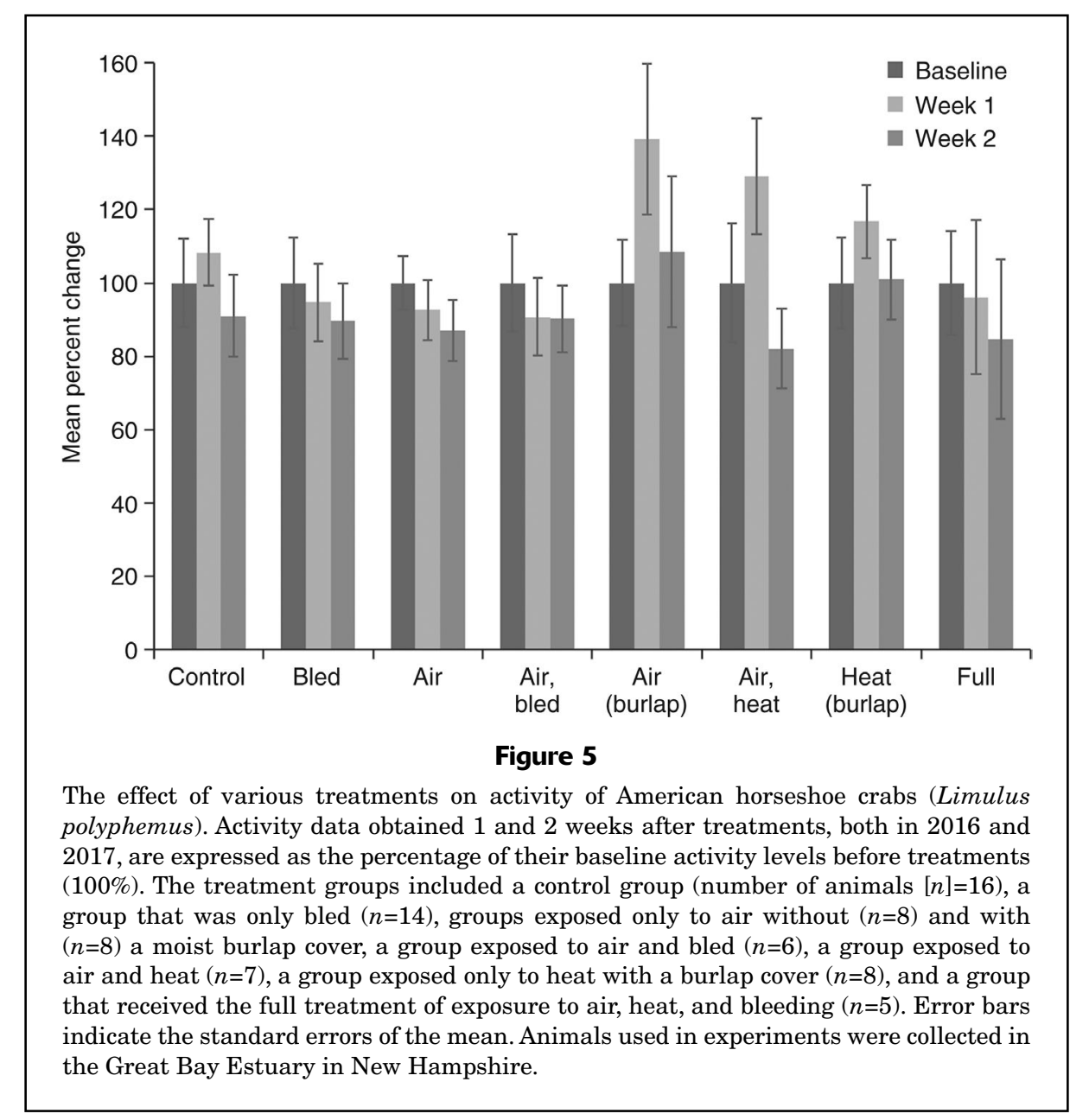

addition, results indicate that there was a seasonal trend in baseline HCY levels, and females had lower starting HCY levels than males during all months sampled.

\section{Mortality}

Throughout all of the trials in this study, mortality rates differed between treatment groups, with an overall mortality rate of $17 \%$ (excluding control animals). Although this overall mortality rate is similar to the estimated range of mortality rates of 5-30\% reported in previous studies (Thompson, 1998; Walls and Berkson, 2000, 2003; Hurton and Berkson, 2006; Leschen and Correia, 2010; Anderson et al., 2013), the upper end of our mortality range (75\% in 2017) is high in comparison to that of many previous studies. The sample size, however, was quite low for the full treatment group in 2017. As a result, we are hesitant to draw any firm conclusions about this finding. We should also point out that the number of mortalities was highest in July, and that was also the case in a recent study that was conducted in a similar manner at JEL $\left(\right.$ Thomas $\left.^{3}\right)$. Therefore, the combination

\footnotetext{
${ }^{3}$ Thomas, T. 2019. Unpubl. data. Plymouth State Univ., 17 High St., Plymouth, NH 03264.
}

of seasonally low HCY levels and high water temperatures might make animals more susceptible to the bleeding process at certain times of the year.

We did not see any mortalities in the control group or in the groups exposed to air, air and heat, or air and heat (with burlap), but the group exposed to air (with burlap) had 2 mortalities. This finding indicates that these stressors on their own are not lethal and that blood loss is the greatest risk factor. This result supports previous findings of a $10-20 \%$ increase in mortality rates in animals that were subjected to only hemolymph extraction compared with the mortality rate of control animals (Rudloe, 1983; Kurz and James-Pirri, 2002).

We had more mortalities in 2017 (27\%) than in 2016 (4\%). This difference could be explained by the fact that we used only males in 2016 and both males and females in 2017. This conclusion is supported by previously reported sex differences in mortality rates (Leschen and Correia, 2010; James-Pirri et al., 2012): 15\% of males and up to $29 \%$ of females. We have ruled out temperature differences between the years because average water temperatures reached $22.3^{\circ} \mathrm{C}$ in 2016 and peaked around $20.7^{\circ} \mathrm{C}$ in 2017 . Finally, the only difference in treatment groups between the 2 years was the addition of burlap to 


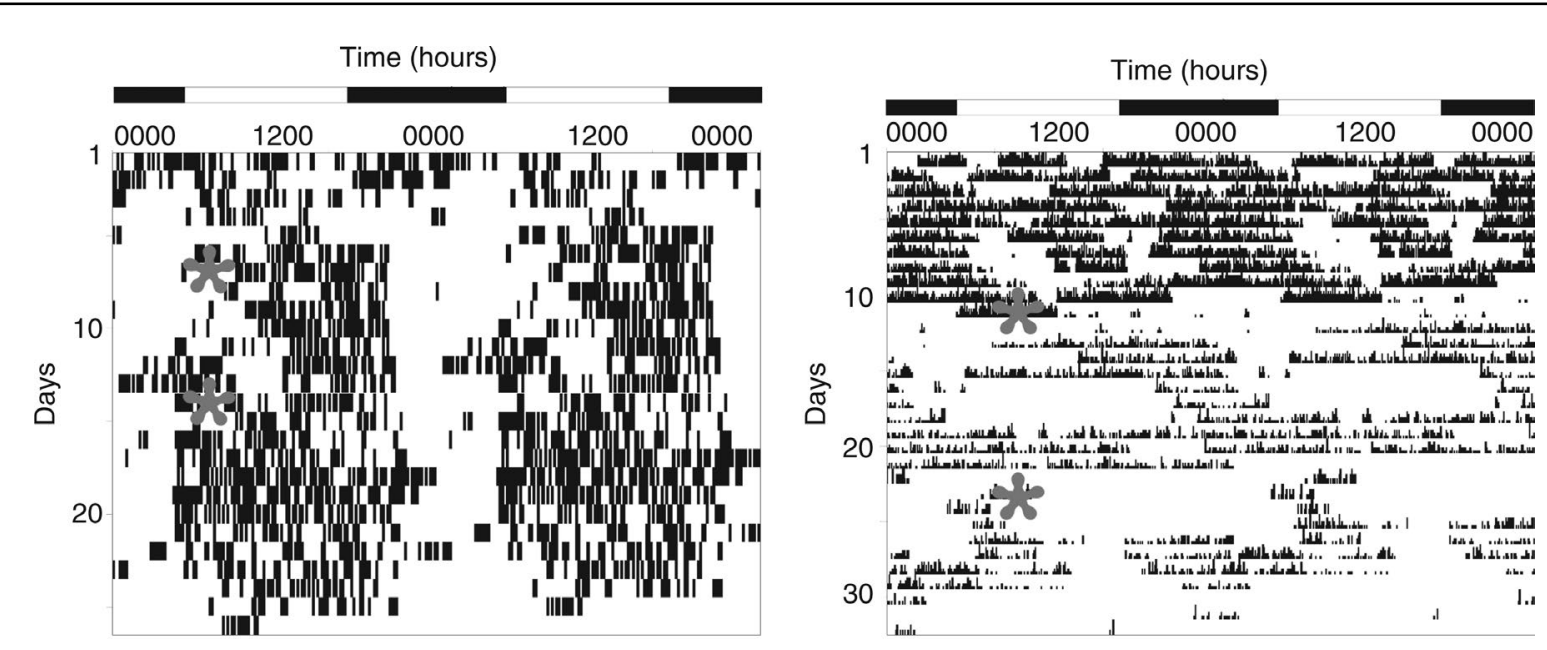

Figure 6

Actograms showing activity over time for American horseshoe crabs (Limulus polyphemus) collected in the Great Bay Estuary in New Hampshire and exposed to stressors in laboratory experiments conducted in 2016. Data are presented for one animal from the control group (left) and one animal from the group that received the full treatment of exposure to air, heat, and bleeding (right). The x-axis is double-plotted, with a span of $48 \mathrm{~h}$, to make rhythms more evident. The white and black horizontal bars at the top of each actogram represent the light and dark periods of the day. Values on the y-axis represent $\sim 4$ weeks of treatment for each animal in October 2016. Large gray asterisks indicate the time of the treatment (top star) and the time 2 weeks posttreatment when data were downloaded from the accelerometer attached to each animal (bottom star). The animal on the right had a tidal rhythm (dominant period: $12.6 \mathrm{~h}$ ) during its treatment.

keep the animals moist in some groups in 2017, and this change was intended to mitigate any lethal or sublethal effects.

When mortalities did occur, the vast majority (14 of 15 mortalities) took place within 1-2 d of the treatment of animals. One possible way to reduce mortalities might be to try to return American horseshoe crabs to their natural environment as soon as possible, an approach that is consistent with the U.S. Food and Drug Administration mandate that American horseshoe crabs be returned within 24-72 h after time of collection $\left(\mathrm{ASMFC}^{4}\right)$.

\section{Hemocyanin levels}

Changes over time We observed several different trends in HCY concentrations, both over time and within treatment groups. First, we saw a decrease in HCY levels over time, especially within the first week, in all groups, including the control group. This decrease is likely due to the animals being kept

\footnotetext{
${ }^{4}$ ASMFC (Atlantic States Marine Fisheries Commission). 1998. Interstate fishery management plan for horseshoe crab. ASMFC Fish. Manage. Rep. 32, 40 p. ASMFC, Arlington, VA. [Available from website.]
}

in captivity and is consistent with results of a previous study in the same location (Anderson et al., 2013). According to Coates et al. (2012), the immune competence of American horseshoe crabs is negatively affected

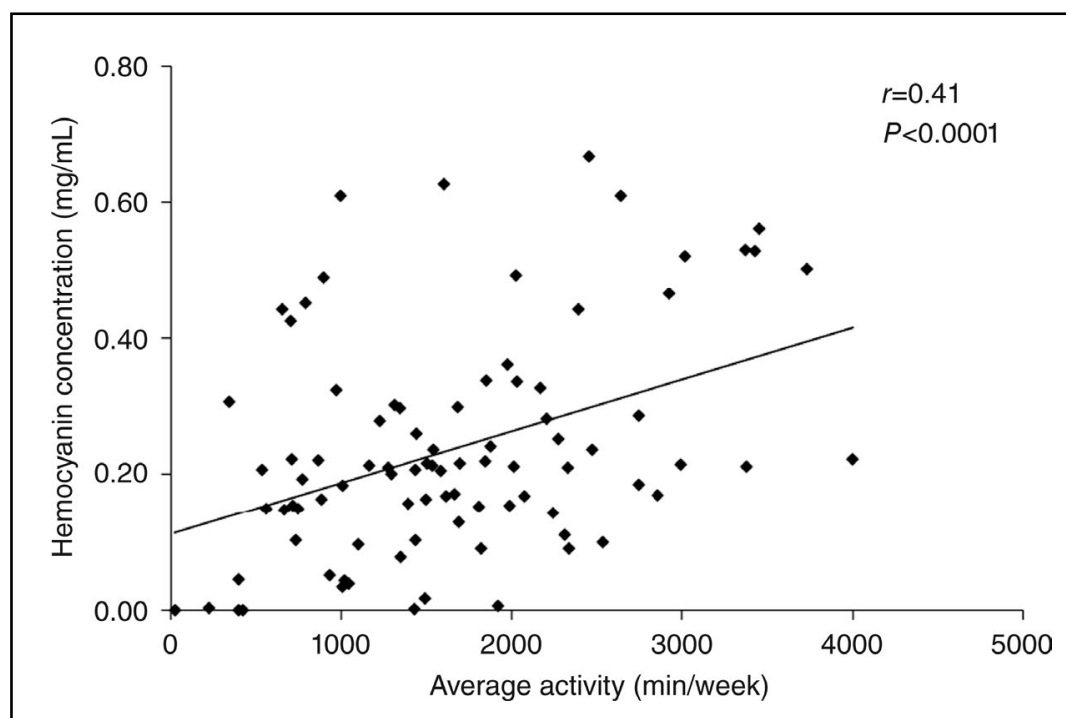

Figure 7

Relationship between hemocyanin and average activity levels of American horseshoe crabs (Limulus polyphemus) collected in the Great Bay Estuary in New Hampshire and used in laboratory experiments in 2016 and 2017 (number of animals $=87$, coefficient of correlation $[r]=0.41, P<0.0001$ ). The diagonal line indicates the trend for the data. 
by the stress associated with holding animals in captivity. The specific effects of low blood protein and HCY levels on American horseshoe crab physiology and behavior has not been well studied to date, except for the observation made over 100 years ago that lower protein levels are associated with starvation and mortality (Alsberg, 1914). More recently, high mortality rates of American horseshoe crabs have been documented in animals kept in captivity. This high mortality appears to be caused by hepatic insufficiency, protein-losing enteropathy, nutritional imbalance or deficiency, and protein-losing nephropathy (Novitsky, 2009; Carmichael and Brush, 2012). These findings support a proposal that would require biomedical facilities to use high-quality water and frequent feeding to maintain the health of American horseshoe crabs that are being held before and after bleeding (Armstrong and Conrad, 2008).

Effects of different treatments We also saw changes in HCY levels due to different treatments, indicating that captivity was not the only factor contributing to decreases in HCY levels over time. In particular, HCY levels were significantly lower in the animals exposed to the full bleeding treatment (air, heat, and bled) than in those exposed to other treatments. The stressor that caused the greatest decrease in HCY levels was heat, a finding that is consistent with previous reports that HCY concentrations decreased as temperatures increased (from $8^{\circ} \mathrm{C}$ to $23^{\circ} \mathrm{C}$ ) (Chen et al., 1995; Hennig and Andreatta, 1998). Coates et al. (2012). To make matters worse, the oxygen affinity of HCY, like other respiratory pigments, decreases as temperature increases (Redfield, 1934; Burnett et al., 1988). Therefore, not only do American horseshoe crabs that experience the biomedical bleeding procedure have less HCY but also the HCY they do have cannot hold as much oxygen. Furthermore, because warmer seawater holds less oxygen than cooler water and animals have a higher metabolism and lower HCY levels at higher temperatures, the combination of stressors could cause long-term hypoxia. Therefore, we suggest that hypoxia could be one major cause of both the mortalities and reduced activity that we, and others, have documented.

Changes in HCY levels might also lead to mortalities or alterations in behavior because of the role that HCY plays in the function of the immune system. Hemocyanin is converted into a phenoloxidase-like enzyme by hemocyte components (Adachi et al., 2003), and the enzymatic oxidation is important in the cuticle formation and immune reaction in arthropods (Ashida and Brey, 1997; Söderhäll and Cerenius, 1998). Therefore, the effects of different factors on hemocyte levels can also have an indirect impact on HCY function, specifically in regards to temperature. For example, in the Atlantic sand fiddler (Uca pugilator), temperature affected clotting times, levels of plasma protein, and total hemocyte numbers (Clare and Lumb, 1994). Seasonal changes in hemocyte antibacterial activity as temperatures change has been observed for another crab species, the green crab (Carcinus maenas) (Chisholm and Smith, 1994). All of these effects of temperature on hemocyte levels indicate that HCY levels could also be affected by high temperatures, especially in the American horseshoe crab.

Air exposure can have negative effects both on its own and in combination with heat and blood loss. As blood flows through the book gills of an American horseshoe crab, gas exchange occurs and HCY becomes saturated with oxygen. During air exposure, the book gills can become desiccated, ventilation ceases, and the heart rate drops considerably. Therefore, little gas exchange takes place and hemolymph circulation throughout the body decreases significantly (Watson and Wyse, 1978; Watson, 1980). As stated previously, heat increases crab metabolism, resulting in a need for more oxygen, and when HCY levels are low, HCY cannot carry as much oxygen. Therefore, the combination of warm temperatures, air exposure, and blood loss could lead to severe hypoxia. Also, amebocytes, the granular cell that plays a crucial role in defending American horseshoe crabs against pathogens, are created through cell differentiation that is sourced from the gill flaps (Gibson and Hilly, 1992). Presumably, then, any harm to the gills could cause amebocyte growth to be hampered and could reduce immune function. However, although exposure to air can have negative impacts on the physiology of American horseshoe crabs, it does not appear to be as detrimental as exposure to heat, perhaps, because the placement of gills on the ventral surface of animals generally produces a microclimate that increases humidity and decreases desiccation. Still, when both stressors are combined, they likely have a synergistic effect.

Hemocyanin composes $90 \%$ of total hemolymph protein in the American horseshoe crab (Ding et al., 2005), and an estimated $30 \%$ of the hemolymph volume is extracted from American horseshoe crabs during the bleeding process. Although they can rapidly regain most of their blood volume, it takes much longer for them to replace the lost HCY. Therefore, HCY concentrations decrease, and this decline in levels can lead to some of the health issues described previously. In this study, we measured HCY levels for only 2 weeks posttreatment, but findings from previous studies indicate that it takes many weeks for HCY levels to recover following bleeding. For example, Anderson et al. (2013) reported that HCY levels were still low after 6 weeks, and James-Pirri et al. (2012) found significantly reduced levels of total hemolymph protein in bled animals compared with levels in control animals $17 \mathrm{~d}$ after bleeding, with bled animals having $20 \%$ less hemolymph protein than control animals.

In summary, the combination of blood loss, exposure to air (which reduces and slows the heart rate; Watson and Wyse, 1978; Watson, 1980), and exposure to heat (which increases metabolism) appears to have the most dramatic impacts on both mortalities and behavior of the American horseshoe crab. Although these same stressors can also have a negative effect on the immune system, in our study the most dramatic effects occurred during the first week after animals were bled; hence, the impacts from various treatments likely occurred too early to have been caused by immunodeficiency or infection. Our 
view is that the impairments caused by the bleeding process are likely a result of the fact that all the stressors involved influence the ability of American horseshoe crabs to obtain sufficient oxygen and to circulate it to all their tissues.

Seasonal and sex differences Another interesting finding from this study was that there were significant effects of season and sex on HCY levels. Concentrations of HCY were the lowest in May and June and the highest in August and September. The spawning season in the Great Bay Estuary in 2016 was 9 May-10 June, and in 2017 it was 16 May-16 June; these seasons correspond to the period during which HCY levels were the lowest. Furthermore, during all months sampled (May-October), females had lower HCY levels than males, especially in May and June. Females have greater variability in their estimated hemolymph volume, likely because females carry eggs that displace space in body cavities that could be filled with hemolymph (Hurton et al., 2005). Although the impact of eggs might explain the lower HCY levels in females in May and June, it does not necessarily account for the consistently lower HCY levels in females, compared with those in males, later in the year or for the low levels of $\mathrm{HCY}$ in males during the spawning season.

Egg production is an energetically expensive process (Bryant and Hartnoll, 1995; Nicol et al., 1995; Guillou and Lumingas, 1999; Chaparro and Flores, 2002; Jørgensen et al., 2006), as is making several trips to spawning beaches within the same season, often with males attached to their carapace. These energetic costs, combined with low HCY levels, might explain, in part, why females are likely to be more heavily affected and physiologically stressed from the bleeding process. This idea is certainly consistent with findings from one of our recent studies indicating that females were less likely than males to have normal activity levels when bled and released into their natural habitat, especially during the spawning season (Owings et al., 2019).

In the past, females have been harvested more than males for bleeding because of their size and larger hemolymph volume. For example, in Pleasant Bay, Massachusetts, $66 \%$ of the American horseshoe crabs collected up until 2001 were female (Rutecki et al., 2004). Captured females also tend to be larger than the average females of the populations in Pleasant Bay because harvesters select for larger females (Rutecki et al., 2004). In this area, over $50 \%$ of the harvest and bleeding occurs during, or shortly after, the spawning season. Because larger females are being selected and these animals are also more fecund (Leschen et al., 2006), this selection practice risks reducing the number of eggs being produced and fertilized over time and may alter population dynamics. Given that females have lower HCY levels throughout the year, have added metabolic costs during spawning, have their lowest HCY levels in the spring during the spawning season, and have higher mortality rates than males when they are bled, it is reasonable to suggest that more attention should be focused on regulating when females can be harvested and making the bleeding process less detrimental to them.

\section{Relationship between hemocyanin levels and mortality}

In this study, we found that animals with lower baseline HCY levels suffered greater sublethal and lethal effects when exposed to multiple stressors from the bleeding process. The baseline HCY levels in animals that died in different treatment groups were significantly lower than in animals that survived in those same treatment groups. The treatment groups that had mortalities included the groups of animals that were exposed to air and heat and were bled (with and without burlap), animals that were exposed to air and were bled (with burlap), and animals exposed to air (with burlap). Therefore, air and bleeding were the most significant stressors because animals in poor initial health that were exposed to these factors were more likely to die.

In order to use this information to reduce mortalities, biomedical facilities might take a hemolymph sample before bleeding animals and proceed to bleed only animals with HCY levels that fall above a certain estimated healthy threshold (we suggest a level later in this paragraph). Facilities already are required to prescreen for injured American horseshoe crabs before bleeding them. If biomedical companies could take this precaution one step further and take an initial blood sample, or develop a faster and easier way to determine the health status of an American horseshoe crab, they could significantly reduce mortality rates. For example, on the basis of data from our study, American horseshoe crabs with a HCY level of $32 \mathrm{mg} / \mathrm{mL}$ or below should not be bled.

The absolute critical level from this study was $13 \mathrm{mg} / \mathrm{mL}$ : any individual that had this baseline HCY level, and was exposed to at least 2 of the different stressors, died. How close animals are to this threshold changes across sexes (with females having lower baseline HCY levels), over a season (with higher HCY levels in late summer and fall), and during the length of time an animal is held in captivity (HCY levels decrease as the amount of time in captivity increases, declines that are probably related to nutrition). The latter point is important to keep in mind because the longer an animal is kept in captivity, or in the holding ponds at the facilities, the more their HCY levels will decrease and eventually they may fall below the critical threshold. In short, mortalities could be reduced if there was a simple way to check HCY levels right before bleeding an American horseshoe crab.

\section{Effects of bleeding and associated stressors on crab behavior}

The stressors associated with the biomedical bleeding process had only a small impact on the overall activity of some of the American horseshoe crabs in this study. However, this effect was greatest and most obvious in animals that started the process with low HCY levels (Fig. 7). In contrast, in some treatment groups, we observed an increase in activity during the first week posttreatment. 
This post-handling hyperactivity is not uncommon in American horseshoe crabs and some crustaceans. Anderson et al. (2013) suggested that this increase in initial activity could have been due to 1) an effort to escape after handling (Rudloe and Hernnkind, 1976); 2) a need to search for food in order to replenish lost energy reserves, as has been reported for the edible crab (Cancer pagurus) (Patterson et al., 2009); or 3) disorientation from the bleeding process (Kurz and James-Pirri, 2002). However, if these explanations were valid, we should have observed increased locomotion by the animals in many of the other treatment groups as well.

Some animals in all the treatment groups changed the types of biological rhythms they expressed during the course of the experiment, with the most clear-cut changes observed in the group of animals exposed to air and heat (with and without burlap). However, it should be noted that the group of animals that were subjected to air, heat, and bleeding in 2017 had a large number of mortalities; therefore, it was difficult to discern the impacts of the full bleeding process on the types of rhythms exhibited by the animals in this group. These findings are similar to those reported by Anderson et al. (2013), but in contrast to our results, they observed a decrease in the expression of tidal rhythms.

Handling might also cause animals to change their behavior and the types of rhythms they express. For every treatment group, we picked animals out of the water either to treat them according to the different stressors they were assigned or to take a blood sample (during the treatment period and 1 week posttreatment). Therefore, when we observed changes in the expression of rhythms 2 weeks posttreatment, it may not have been a delayed effect from the bleeding process but a response to being handled. For example, even 2 of the 16 control animals switched from a tidal rhythm to a daily rhythm after they were handled, and in cases where treated animals changed rhythms after about 2 weeks, the shifts almost always occurred right after they were handled. This switch in behavior after handling is not uncommon, and it took place in a number of cases in a previous study of feeding and handling (senior author, unpubl. data).

Nevertheless, despite the occasional animal that changed activity immediately following handling late in a trial, it should be noted that no control animals changed rhythms after they were handled and sampled following the 1-week control period. In contrast, there were many other animals that were clearly impacted by the treatments: these animals changed the rhythms they expressed after their treatments and kept the new activity rhythm throughout the remainder of the experiment, even after the handling associated with the blood sampling done over the 2-week period after treatment. Therefore, as indicated by results from a number of previous studies, the biomedical bleeding process has both lethal and sublethal effects. Moreover, given the data obtained during this study, exposure to warm temperatures and losing a significant amount of blood appear to have the greatest impacts on the behavior and physiology of the American horseshoe crab.

\section{Acknowledgments}

This research project could not have been completed without the help of D. Shay and the staff of the University of New Hampshire JEL. We would also like to thank all the graduate and undergraduate students at the University of New Hampshire and Plymouth State University who helped us with many aspects of this work. This study was supported by a Leslie S. Hubbard Marine Program Endowment grant and Marine Biology Graduate Program grant to the senior author and by funding from New Hampshire Sea Grant (R/HCE-4) to C. Chabot and W. Watson.

\section{Literature cited}

Adachi, K., T. Hirata, T. Nishioka, and M. Sakaguchi.

2003. Hemocyte components in crustaceans convert hemocyanin into a phenoloxidase-like enzyme. Comp. Biochem. Physiol. B 134:135-141. Crossref

Adachi, K., H. Endo, T. Watanabe, T. Nishioka, and T. Hirata. 2005a. Hemocyanin in the exoskeleton of crustaceans; enzymatic properties and immunolocalization. Pigment Cell Res. 18:136-143. Crossref

Adachi, K., K. Wakamatsu, S. Ito, N. Miyamoto, T. Kokubo, T. Nishioka, and T. Hirata.

2005b. An oxygen transporter hemocyanin can act on the late pathway of melanin synthesis. Pigment Cell Res. 18:214219. Crossref

Alsberg, C. L.

1914. Note on the proteins of the blood of Limulus Polyphemus L. J. Biol. Chem. 19:77-82.

Anderson, R. L., W. H. Watson III, and C. C. Chabot.

2013. Sublethal behavioral and physiological effects of the biomedical bleeding process on the American horseshoe crab, Limulus Polyphemus. Biol. Bull. 225:137-151. Crossref

Armstrong, P., and M. Conrad.

2008. Blood collection from the American horseshoe crab, Limulus polyphemus. J. Vis. Exp. 20:e958. Crossref

Ashida, M., and P. Y. Brey.

1997. Recent advances in prophenoloxidase research. In Molecular mechanisms of the insect immune response (P. T. Brey and D. Hultmark, eds.), p. 135-172. Chapman and Hall, London.

ASMFC (Atlantic States Marine Fisheries Commission).

2019. 2019 horseshoe crab benchmark stock assessment and peer review report, 237 p. ASMFC, Arlington, VA. [Available from website.]

Bryant, A. D., and R. G. Hartnoll.

1995. Reproductive investment in two spider crabs with different breeding strategies. J. Exp. Mar. Biol. Ecol. 188:261275. Crossref

Burnett, L. E.

1988. Physiological responses to air exposure: acid-base balance and the role of branchial water stores. Am. Zool. 28:125-135. Crossref

Burnett, L. E., D. A. Scholnick, and C. P. Mangum.

1988. Temperature sensitivity of molluscan and arthropod hemocyanins. Biol. Bull. 174:153-162. Crossref

Carmichael, R. H., and E. Brush.

2012. Three decades of horseshoe crab rearing: a review of conditions for captive growth and survival. Rev. Aquac. 4:32-43. Crossref 
Chaparro, O. R., and M. L. Flores.

2002. Reproductive output of Crepidula fecunda females: distribution of energy in the production of gametes and capsular walls. N.Z. J. Mar. Freshw. Res. 36:661-673. Crossref

Chen, J.-C., M.-N. Lin, Y.-Y. Ting, and J.-N. Lin.

1995. Survival, haemolymph osmolality and tissue water of Panaeus chinensis juveniles acclimated to different salinity and temperature levels. Comp. Biochem. Physiol. A 110:253-258. Crossref

Chisholm, J. R. S., and V. J. Smith.

1994. Variation of antibacterial activity in the haemocytes of the shore crab, Carcinus maenas, with temperature. J. Mar. Biol. Assoc. U.K. 74:979-982. Crossref

Clare, A. S., and G. Lumb.

1994. Identification of haemocytes and their role in clotting in the blue crab, Callinectes sapidus. Mar. Biol. 118:601610. Crossref

Coates, C. J., S. M. Kelly, and J. Nairn.

2011. Possible role of phosphatidylserine-hemocyanin interaction in the innate immune response of Limulus polyphemus. Dev. Comp. Immunol. 35:155-163. Crossref

Coates, C. J., E. L. Bradford, C. A. Krome, and J. Nairn.

2012. Effect of temperature on biochemical and cellular properties of captive Limulus polyphemus. Aquaculture 334337:30-38. Crossref

Ding, J. L., K. C. Tan, S. Thangamani, N. Kusuma, W. K. Seow,

T. H. H. Bui, J. Wang, and B. Ho.

2005. Spatial and temporal coordination of expression of immune genes during Pseudomonas infection of the horseshoe crab, Carcinoscorpius rotundicauda. Genes Immun. 6:557-574. Crossref

Gibson, D. G., III, and J. B. Hilly.

1992. Production of horseshoe crab amebocytes in vitro. U.S. Patent 5,082,782, filed 27 December 1988 and issued 21 January 1992.

Glazer, L., M. Tom, S. Weil, Z. Roth, I. Khalaila, B. Mittelman, and A. Sagi.

2013. Hemocyanin with phenoloxidase activity in the chitin matrix of the crayfish gastrolith. J. Exp. Biol. 216:1898 1904. Crossref

Guillou, M., and L. J. L. Lumingas.

1999. Variation in the reproductive strategy of the sea urchin Spaerechinus granularis (Echinodermate: Echinoidea) related to food availability. J. Mar. Biol. Assoc. U.K. 79:131136. Crossref

Hatch, A. C., and A. R. Blaustein.

2003. Combined effects of UV-B radiation and nitrate fertilizer on larval amphibians. Ecol. Appl. 13:1083-1093. Crossref

Hennig, O. L., and E. R. Andreatta.

1998. Effect of temperature in an intensive nursery system for Penaeus paulensis (Pérez Farfante, 1967). Aquaculture 164:167-172. Crossref

Hurton, L., and J. Berkson.

2006. Potential causes of mortality for horseshoe crabs (Limulus polyphemus) during the biomedical bleeding process. Fish. Bull. 104:293-298.

Hurton, L., J. Berkson, and S. Smith.

2005. Estimation of total hemolymph volume in the horseshoe crab Limulus polyphemus. Mar. Freshw. Behav. Physiol. 38:139-147. Crossref

James-Pirri, M.-J., P. A. Veillette, and A. S. Leschen.

2012. Selected hemolymph constituents of captive, biomedically bled, and wild caught adult female American horseshoe crabs (Limulus polyphemus). Mar. Freshw. Behav. Physiol. 45:281-289. Crossref
Jørgensen, C., B. Ernande, Ø. Fiksen, and U. Dieckmann.

2006. The logic of skipped spawning in fish. Can. J. Fish. Aquat. Sci. 63:200-211. Crossref

Krisfalusi-Gannon, J., W. Ali, K. Dellinger, L. Robertson, T. E. Brady, M. K. M. Goddard, R. Tinker-Kulberg, C. L. Lepley, and A. L. Dellinger.

2018. The role of horseshoe crabs in the biomedical industry and recent trends impacting species sustainability. Front. Mar. Sci. 5:185. Crossref

Kuballa, A. V., and A. Elizur.

2008. Differential expression profiling of components associated with exoskeletal hardening in crustaceans. BMC Genomics 9:575. Crossref

Kuballa, A. V., T. A. Holton, B. Peterson, and A. Elizur.

2011. Moult cycle specific differential gene expression profiling of the crab Portunus pelagicus. BMC Genomics 12:147. Crossref

Kurz, W., and M. J. James-Pirri.

2002. The impact of biomedical bleeding on horseshoe crab, Limulus polyphemus, movement patterns on Cape Cod, Massachusetts. Mar. Freshw. Behav. Physiol. 35:261-268. Crossref

Leschen, A. S., and S. J. Correia.

2010. Mortality in female horseshoe crabs (Limulus polyphemus) from biomedical bleeding and handling: implications for fisheries management. Mar. Freshw. Behav. Physiol. 43:135-147. Crossref

Leschen, A. S., S. P. Grady, and I. Valiela.

2006. Fecundity and spawning of the Atlantic horseshoe crab, Limulus polyphemus, in Pleasant Bay, Cape Cod, Massachusetts, USA. Mar. Ecol. 27:54-65. Crossref

Mangum, C. P. 1980. Respiratory function of hemocyanins. Am. Zool. 20:19-38.

Nicol, S., W. De La Mare, and M. Stolp.

1995. The energetic cost of egg production in Antarctic krill (Euphausia superba). Antarct. Sci. 7:25-30. Crossref

Novitsky, T. J.

1984. Discovery to commercialization: the blood of the horseshoe crab. Oceanus 27:13-18.

2009. Biomedical applications of Limulus amebocyte lysate. In Biology and conservation of horseshoe crabs (J. T. Tanacredi, M. L. Botton, and D. R. Smith, eds.), p. 315-329. Springer, Boston, MA.

Owings, M., C. Chabot, and W. Watson III.

2019. Effects of the biomedical bleeding process on the behavior of the American horseshoe crab, Limulus polyphemus, in its natural habitat. Biol. Bull. 236:207-223. Crossref

Patterson, L., J. T. A. Dick, and R. W. Elwood.

2009. Claw removal and feeding ability in the edible crab, Cancer pagurus: implications for fishery practice. Appl. Anim. Behav. Sci. 116:302-305. Crossref

Paul, R. J., and R. Pirow.

1998. The physiological significance of respiratory proteins in invertebrates. Zoology 100:298-306.

Redfield, A. C.

1934. The haemocyanins. Biol. Rev. 9:175-212. Crossref

Redmond, J. R.

1955. The respiratory function of hemocyanin in crustacea. J. Cell. Comp. Physiol. 46:209-247. Crossref

Rudloe, A.

1983. The effect of heavy bleeding on mortality of the horseshoe crab, Limulus polyphemus, in the natural environment. J. Invertebr. Pathol. 42:167-176. Crossref

Rudloe, A., and W. F. Herrnkind.

1976. Orientation of Limulus polyphemus in the vicinity of breeding beaches. Mar. Behav. Physiol. 4:75-89. Crossref 
Rutecki, D., R. H. Carmichael, and I. Valiela.

2004. Magnitude of harvest of Atlantic horseshoe crabs, Limulus polyphemus, in Pleasant Bay, Massachusetts. Estuaries 27:179-187. Crossref

Schisler, G. J., E. P. Bergersen, and P. G. Walker.

2000. Effects of multiple stressors on morbidity and mortality of fingerling rainbow trout infected with Myxobolus cerebralis. Trans. Am. Fish. Soc. 129:859-865. Crossref

Schmid, B., C. Helfrich-Förster, and T. Yoshii.

2011. A new imageJ plugin "ActogramJ" for chronobiological analyses. J. Biol. Rhythms 26:464-467. Crossref

Schulz, R., and J. M. Dabrowski.

2001. Combined effects of predatory fish and sublethal pesticide contamination on the behavior and mortality of mayfly nymphs. Environ. Toxicol. Chem. 20:2537-2543. Crossref

Söderhäll, K., and L. Cerenius.

1998. Role of the prophenoloxidase-activating system in invertebrate immunity. Curr. Opin. Immunol. 10:23-28. Crossref
Thompson, M.

1998. Assessments of the population biology and critical habitat for the horseshoe crab, Limulus polyphemus, in the South Atlantic Bight. M.S. thesis. Univ. Charleston, Charleston, SC.

Walls, E. A., and J. M. Berkson.

2000. Effects of blood extraction on the mortality of the horseshoe crab, Limulus polyphemus. Va. J. Sci. 51:195-198. 2003. Effects of blood extraction on horseshoe crabs (Limulus polyphemus). Fish. Bull. 101:457-459.

Watson, W. H., III.

1980. Long-term patterns of gill cleaning, ventilation and swimming in Limulus. J. Comp. Physiol. 141:77-85. Crossref

Watson, W. H., III, and G. A. Wyse.

1978. Coordination of the heart and gill rhythms in Limulus. J. Comp. Physiol. 124:267-275. Crossref

Watson, W. H., III, S. K. Johnson, C. D. Whitworth, and C. C. Chabot. 2016. Rhythms of locomotion and seasonal changes in activity expressed by horseshoe crabs in their natural habitat. Mar. Ecol. Prog. Ser. 542:109-121. Crossref 